\title{
The Health Status of Patients of a Student-Run Free Medical Clinic in Inner-City Buffalo, NY
}

\author{
Renee B. Cadzow, MA, Timothy J. Servoss, MS, and Chester H. Fox, MD
}

Background: This study explores the health status and the social and economic correlates of adults 20 years of age and older who presented at an urban free medical clinic in Buffalo, NY, between 2002 and 2005.

Methods: Clinic staff asked patients to fill out a Health Risk Assessment questionnaire that addressed their chronic disease and illness history, mental health, social support, substance use, income, education, and housing. Through statistical analysis of 469 anonymous patient questionnaires, we identified prevalent health conditions in this patient population and compared these rates to regional and national data.

Results: Of those patients 20 years of age and older, $70 \%$ earned less than US $\$ 10,000$ a year. The rates of obesity, hypertension, asthma, diabetes, anxiety, and depression were higher in this population than in the Buffalo, NY, region and the general United States population.

Conclusion: The data reflect the health disparity experienced by low-income minority populations in the United States and emphasize a need to plan additional services that target hypertension, heart disease, obesity, diabetes, and mental health disorders such as anxiety and depression. Findings also serve as an introduction to the patient population for volunteer medical students who have limited exposure to urban, low-income populations. (J Am Board Fam Med 2007;20:572-580.)

When it comes to health, the United States ranks 24th among 191 nations. ${ }^{1}$ The United Kingdom, Canada, and Japan, to name a few, have higher health rankings, higher life expectancies, lower infant mortality rates, and lower health expense per capita. ${ }^{1,2}$ These nations provide health care coverage universally, whereas 46.6 million United States residents $(15.9 \%)$ are without health insurance. ${ }^{3}$ This is equivalent to more than 2 times the population of New York state. ${ }^{4}$ Among the uninsured, African-Americans are disproportionately represented, with $19.6 \%$ lacking health insurance. ${ }^{5}$

This article was externally peer reviewed.

Submitted 1 February 2007; revised 12 July 2007; accepted 19 July 2007.

From the Department of Family Medicine, Primary Care Research Institute (CHF, RBC, TJS), and the Department of Anthropology (RBC), State University of New York at Buffalo, Buffalo; and the Department of Psychology, Canisius College (TJS), Buffalo, NY.

Funding: none.

Conflict of interest: none declared.

Corresponding author: Renee B. Cadzow, MA, Department of Family Medicine, State University of New York at Buffalo, ECMC Clinical Center, CC-119, 462 Grider Street, Buffalo, NY 14215 (E-mail: rcadzow@buffalo.edu).
Social safety net services such as Medicaid and Medicare provide free or reduced-cost insurance to some people who lack employment, are disabled, or whose jobs do not provide health insurance. There are many other people, though, who exceed the income limits to receive free health care coverage but make an insufficient income to pay out-of-pocket for their health insurance. ${ }^{6}$ Among those uninsured, nearly $70 \%$ come from a family with at least one full-time worker. ${ }^{5,7}$ Twenty-eight percent of the uninsured are parttime workers. ${ }^{5,7}$ Free clinics across the United States have functioned to partially patch this hole in the safety net by providing care to the underand uninsured. ${ }^{8,9}$

Free medical clinics are typically staffed by volunteer physicians, nurse practitioners, and nurses, and often also include a dental care component. Most offer standard triage care and physical exams; some offer services such as screening for sexually transmitted diseases. The importance of free medical clinics as part of the health care safety net was underscored by a survey of 106 free clinics in the Midwestern United States that showed they cared for over 200,000 patients in a single year. ${ }^{10}$ 
Recently, free medical clinics have been established by students in medical schools or by the schools themselves. Student-run clinics operate with a variety of underserved populations, including migrant workers, rural Appalachian communities, and the homeless. ${ }^{11-13}$ Some student initiatives take place outside of the clinic setting, and include home care visits with geriatric patients, providing health care information to emergency department patients, and conducting behavioral counseling as part of a smoking intervention. ${ }^{14-16}$ According to a recent survey, there are at least 111 medical student-run clinics associated with 29 medical schools in 25 states. ${ }^{17}$ Most of the publications generated from these endeavors describe the demographics of the patients served, the structure of the programs, and the educational benefit to students (both medical and patient-communication skills). ${ }^{8-20}$ To our knowledge, none have described the health status of the patients served by the clinics and the primary health risks that they face. Although there has been considerable recent attention to health disparities experienced by the underserved, it is important (particularly for medical students) to recognize that underserved patients are not all the same; they are a heterogeneous population and care must be adapted to the unique circumstances of local communities. This is a report on one such local community.

The objective of this analysis is to discuss the results of a detailed health risk assessment questionnaire administered to a population of free clinic patients and the utility of such a questionnaire. We will describe the health risks of this particular patient population and discuss the application of this information to improving patient services and preparing new volunteer medical students.

\section{Background}

The Lighthouse Free Medical Clinic was founded in 2001 as a collaboration between the pastor of a Lutheran church, a family physician, and a group of 5 medical students. The site was selected because of its location in a Health Professional Shortage Area. ${ }^{21}$ In the Census tracts within a 1-mile radius of the clinic, $38 \%$ of households live below the poverty level (more than 3 times the national rate) and approximately $17 \%$ of the workforce is unemployed. Twenty percent (20\%) of the households receive public assistance income (eg, food stamps, housing subsidy, etc). The population is $80.8 \%$ African-American and $16 \%$ white. Thirty-three percent of the housing stock is vacant, ${ }^{22}$ creating a neighborhood environment of boarded up, dilapidated structures with broken windows and debris scattered about.

The clinic operates from 6 to 8 PM on Wednesdays; patients are seen on a drop-in basis and approximately 25 patients are seen per night. Ages range from infancy to elderly, with approximately $48 \%$ being 19 years old or younger. Services are limited to screening and triage because of limited hours of the volunteer staff (which includes medical students, nurse practitioners, and physicians). More than 1500 people sought care at the clinic between 2001 and 2005. Medical reasons given by patients for coming to the clinic included physicals for school sports or work (53\%), illnesses (35\%), and free prescription refills $(12 \%){ }^{23}$ Other reasons cited by patients included convenience of the location, lack of health insurance, wanting an alternative to the emergency department for care, and a desire to not incur any new medical costs. ${ }^{24}$ The clinic does not charge patients or bill the insurance of those who are insured; approximately $55 \%$ of the adult patient population is uninsured and $45 \%$ have some form of health insurance.

\section{Methods}

As part of their visit to the free clinic, starting in 2002 patients were asked to complete a Health Risk Assessment Questionnaire addressing issues such as income, education, employment, self-report of disease, social environment, and housing. Nested within the questionnaire were 2 validated instruments: the Primary Care Evaluation of Mental Disorders form (PRIME-MD) for assessing a mental health disorder and the CAGE questionnaire (named for its 4 questions) for assessing alcohol abuse. ${ }^{25-29}$ The PRIME-MD assesses the possible presence of somatoform disorder, eating disorder, depression risk, and anxiety. It asks, In the past month have you been bothered a lot by. . . ?, and then lists a number of different emotions or bodily ailments that may indicate the presence of 1 or more of the 4 aforementioned mental health disorders. The CAGE instrument determines whether someone is at-risk for alcohol problems by asking 4 questions: Have you ever felt you should $C$ ut down on your drinking? Have you ever felt $A$ nnoyed by 
complaints about your drinking? Have you ever felt bad or Guilty about your drinking? and Have you ever had a drink first thing in the morning (Eyeopener) to steady your nerves or get rid of a hangover? For each item, Never $=0$, Occasionally $=1$, and Often $=2$. The scores of the 4 items are added and a score of 2 or greater qualifies as at-risk for alcohol problems.

One thousand four patients who presented to the clinic during this time period completed at least a portion of the questionnaire. Because many of the questionnaires lacked a response to 1 or more of the questions, a cutoff of $80 \%$ completion was established. Those with more than 8 questions unanswered ( $>20 \%)$ were removed from the dataset. Questionnaires that were at least $80 \%$ complete (32 of 40 questions answered) were included, leaving a final sample of 986 questionnaires, each representing an individual patient. For this study, most analyses were limited to adults 20 years of age and older, leaving a sample of 469 patients. Patients who were younger than 20 constituted a somewhat different population, not only because of their age, but also because the majority were visiting the clinic for free school sports physicals.

Patient identification was removed from the survey responses, which were then analyzed using SPSS version 14.0 (SPSS Inc., Chicago, IL). Descriptive statistics were used to generate a picture of the population's demographics and their disease frequency, and $\chi^{2}$ tests determined the significance of relationships between health conditions and the sociodemographic variables. The study was approved by the University at Buffalo Health Sciences Institutional Review Board.

\section{Results}

\section{Demographics (Table 1)}

Of those patients 20 years of age and older $(n=469)$, $64 \%$ were women and most self-identified as AfricanAmerican (87\%). More than two-thirds (68.6\%) of these patients had an annual income of less than $\$ 10,000$, and $43 \%$ earned less than $\$ 5,000$ a year. Although $29.1 \%$ had less than a high school education, $41.5 \%$ had some training after high school and $11.8 \%$ had a college degree. Nearly half were employed full-time $(27.2 \%)$ or part-time (20.9\%). Of those who did not have paid employment, 33.1\% were looking for work, $22.7 \%$ were not working because of medical reasons, and $17.2 \%$ were students.
Table 1. Demographics of Adult Patients $(n=469)$ at Student-run Free Clinic*

\begin{tabular}{|c|c|c|}
\hline Characteristic & $\begin{array}{l}\text { Patients } \\
\text { From } \\
\text { LFMC } \\
(\%)\end{array}$ & $\begin{array}{c}\text { Western } \\
\text { New York } \\
\text { (\%) }\end{array}$ \\
\hline \multicolumn{3}{|l|}{$\operatorname{Sex}(n=446)$} \\
\hline Male & 35.7 & 47 \\
\hline Female & 64.3 & 53 \\
\hline \multicolumn{3}{|l|}{ Age range $(n=469)$} \\
\hline $20-29$ & 29.4 & NA \\
\hline $30-39$ & 27.3 & NA \\
\hline $40-49$ & 26.2 & NA \\
\hline $50-59$ & 11.3 & NA \\
\hline$\geq 60$ & 5.8 & NA \\
\hline \multicolumn{3}{|l|}{ Race/ethnicity ( $\mathrm{n}=431$ ) } \\
\hline African-American & 86.8 & 4 \\
\hline White & 9.0 & 93 \\
\hline Other & 1.2 & 2 \\
\hline Hispanic & 3.0 & 2 \\
\hline \multicolumn{3}{|l|}{ Level of education $(n=408)$} \\
\hline$\leq 8$ th grade & 2.9 & NA \\
\hline Some high school & 26.2 & NA \\
\hline High school graduate/GED & 29.4 & NA \\
\hline Some college/training after high school & 29.7 & NA \\
\hline College graduate & 8.6 & NA \\
\hline Postgraduate education or degree & 3.2 & NA \\
\hline \multicolumn{3}{|l|}{ Paid employment status $(\mathrm{n}=412)$} \\
\hline Not in paid employment & 48.1 & NA \\
\hline Full-time & 27.2 & NA \\
\hline Part-time & 20.9 & NA \\
\hline Self-employed & 3.8 & NA \\
\hline \multicolumn{3}{|l|}{ Not in paid employment $(\mathrm{n}=163)$} \\
\hline Looking for work & 33.1 & NA \\
\hline Disabled/medical reason & 22.7 & NA \\
\hline Student & 17.2 & NA \\
\hline Homemaker & 7.4 & NA \\
\hline Retired & 6.7 & NA \\
\hline Laid off & 6.7 & NA \\
\hline Other & 6.2 & NA \\
\hline \multicolumn{3}{|l|}{ Average yearly income $(n=386)$} \\
\hline$<\$ 10,000$ & 68.6 & 19 \\
\hline
\end{tabular}

*Unduplicated self-report data from Health Risk Assessment Questionnaire administered to patients presenting at clinic. LFMC, Lighthouse Free Medical Clinic; GED, General Education Development; NA, not available.

Fifteen percent of the patients had no working phone in the previous 6 months and 9\% reported being homeless at some point in the previous 6 months.

\section{Chronic Disease}

Among adults, the most prevalent of the queried physical conditions were obesity, hypertension, ar- 
Table 2. Frequency of Health Conditions Among Adult Patients at a Student-run Clinic $(n=469)$

\begin{tabular}{|c|c|c|c|c|c|}
\hline Physical Conditions & $\begin{array}{c}\text { Free Clinic } \\
(\%)\end{array}$ & $\begin{array}{c}\text { Region } \\
(\%)\end{array}$ & Mental Conditions & $\begin{array}{c}\text { Free Clinic } \\
(\%)\end{array}$ & $\begin{array}{c}\text { Region } \\
(\%)\end{array}$ \\
\hline Obesity* & 40.2 & 18.4 & PRIME-MD somatoform & 33.5 & NA \\
\hline Hypertension $^{\dagger}$ & 25.6 & 16.6 & PRIME-MD anxiety & 30.1 & NA \\
\hline Asthma $^{\dagger}$ & 12.8 & 7.0 & Anxiety $^{\dagger}$ & 6.8 & 4.8 \\
\hline Arthritis $^{\dagger}$ & 11.5 & 18.2 & PRIME-MD depression & 13.0 & NA \\
\hline High cholesterol $^{\dagger}$ & 11.5 & 12.3 & Depression $^{\dagger}$ & 9.0 & 5.2 \\
\hline Diabetes $^{\dagger}$ & 8.1 & 6.1 & PRIME-MD eating disorder & 6.0 & NA \\
\hline
\end{tabular}

*Percentages based on measurements taken in physical exam. $\mathrm{n}=381$.

${ }^{\dagger}$ Response to questionnaire item asking if patient has ever been diagnosed with the conditions by a health professional.

PRIME-MD, Primary Care Evaluation of Mental Disorders; NA, not available. Regional values are from reference 42.

thritis, high cholesterol, diabetes, and asthma (Table 2).

Those with less than a high school education had a higher prevalence of diabetes, hypertension, and history of heart attack $(P<.05)$. Compared with men, women had higher rates of obesity, high blood pressure, high cholesterol, and heart conditions $(P<.05$ for all variables).

\section{Mental Health}

Patients 30 years of age and older had high rates of mental health conditions. Seven percent $(7 \%)$ of adults indicated they had been diagnosed with anxiety and 9\% with depression. The PRIME-MD instrument indicated that $37.2 \%$ may have somatoform disorder, $32 \%$ may have anxiety, and 13\% may have depression. These rates of anxiety and depression are substantially higher than the selfreported diagnosed rates. Women had higher rates of some mental health disorders than did men. Approximately $40 \%$ of adult women in the study population may have somatoform disorder compared with approximately $23 \%$ of adult men, and $33 \%$ of women may have anxiety compared with $24 \%$ of men. Women also had higher rates of depression as indicated by the PRIME-MD, though it was not significant. Interestingly, there were no significant differences between men and women in the self-reported diagnosed rates of mental health disorders.

\section{Substance Use}

As one would expect, smoking was associated with both physical and mental health conditions. Approximately $40 \%$ of those 20 years of age and older were current smokers and $18 \%$ were former smokers. Being a smoker was associated with higher rates of reporting a heart condition and having had a heart attack. In addition, being a smoker was associated with screening positive for somatoform disorder, depression, and anxiety.

Thirteen percent (54 of 410) of CAGE respondents had a positive score. Compared with those respondents not at risk for alcohol problems, those who were at risk had higher rates of depression as scored by the PRIME-MD (25.9\% vs $12.9 \%)$ and self-reported having been diagnosed with depression and anxiety $(14.8 \%$ vs $5.3 \%$ and $11.1 \%$ vs $3.4 \%$, respectively).

\section{Discussion}

Higher morbidity and mortality is experienced by people living in poverty. ${ }^{30-33}$ When compared with people of higher socioeconomic status, those with low socioeconomic status often have lower educations; poor access to well-paying jobs; sedentary lifestyles; hazardous home environments (eg, lead paint, asbestos, dilapidated structures); poor nutrition; and they are less likely to have comprehensive health insurance. ${ }^{34-37}$ In addition, those who are uninsured experience higher rates of premature death than do those who are insured. The uninsured or underinsured poor often seek health care only as a last resort. ${ }^{38}$ They then rely on emergency rooms, which are among the most expensive forms of treatment. The cost of injuries, illnesses, births, and prescriptions are prohibitive for a low-income person. Many of these characteristics of poverty populations were found in this free clinic patient population.

The proportion of uninsured patients at the Lighthouse Clinic is high (55\%), though considerably lower than in similar studies conducted in free 
medical clinics where the uninsured comprised more than $80 \%$ of the patient population. ${ }^{39}$ A survey of free clinics in the Midwestern United States found that $93 \%$ of free clinic patients had no health insurance. ${ }^{8}$ Among the medical student-run clinics, $88 \%$ of those responding to a survey provide care to the uninsured, but the percentage of uninsured patients is not provided. ${ }^{17}$ One possible explanation for the high numbers of insured presenting at this clinic is the convenience of the clinic compared with other area medical facilities. At the time of the study, it was the only clinic within a 3 -mile radius and it was along a bus route. In addition, patients mentioned the cost of co-pays as a deterrent to seeking care at other types of health care facilities. ${ }^{23}$

General trends show that health care facilities have a 70:30 distribution of female to male patients, and a nearby urban family medical center has a patient population that is $67 \%$ female. Similarly, $64 \%$ of the Lighthouse Free Medical Clinic adult patients were women.

A strong association between education and health has been well-established in research of the last decade. Staying in school seems related to reduced chances of having chronic illness and dying prematurely. In the Lighthouse population this is reflected in the rates of chronic diseases of those with more than a high school education compared with those with less education. Possible reasons for this include more health-related knowledge, access to better jobs, access to health care, and thus, presumably (and evidently), less daily stress. ${ }^{40,41}$

Compared with results from a health risk assessment questionnaire conducted in 2117 households in Western New York in 1999, this free clinic population has higher rates of obesity and medically diagnosed hypertension, asthma, diabetes, anxiety, and depression. ${ }^{42}$ The high level of obesity in this population is probably related to the high level of diabetes and heart disease. The trend seems to start in childhood and adolescence, as indicated by one-third of adolescents (32\%) in the patient population at-risk for becoming overweight or already overweight (above the 85 th and 95 th percentiles, respectively). The incidence of adult and adolescent obesity may be associated with a number of issues that are often faced by low-income populations. There is limited access to safe places to play and exercise and to grocery stores that have reasonable prices and fresh foods. ${ }^{43}$ People living in poverty also often consume inexpensive foods, which tend to be high in carbohydrates, sugar, and fat. ${ }^{44}$ High life stress may trigger overeating as a coping strategy, and the body's stress response may also cause fat to deposit centrally (around the waist) rather than elsewhere, causing a higher strain on the heart. ${ }^{45,46}$

The self-reported, medically diagnosed rates of depression and anxiety were higher than those from the regional study; the rates of depression and anxiety as indicated by the PRIME-MD were substantially higher than both the regional study and the self-reported medically diagnosed rates. ${ }^{42}$ The PRIME-MD instrument indicated that $37.2 \%$ may have somatoform disorder, $32 \%$ may have anxiety, and $13 \%$ may have depression. This exceeds the national average, where it was found that depression affects approximately $7 \%$ of the United States population and $18 \%$ experience some type of anxiety disorder nationwide. ${ }^{47,48}$ Interestingly, the rates of self-reported, medically diagnosed anxiety are lower in both samples compared with the United States population $(16.4 \%$ in the United States have been diagnosed with any anxiety disorder compared with $7 \%$ in the Lighthouse population and $5 \%$ in the regional study). ${ }^{48}$

The frequency of mental health disorders as indicated by self-report compared with that indicated by the PRIME-MD instrument, and because some of these rates are lower than the national rates, suggests that anxiety and depression may be under-diagnosed in this population. For example, the PRIME-MD indicated that $32.3 \%$ of adults may be at risk for anxiety compared with $6.8 \%$ who reported they had been told they had anxiety by a health professional. United States data suggest that African-Americans actually experience higher rates of mental health disorders compared with the general population because of higher proportions of African-Americans having low socioeconomic status. ${ }^{48}$ African-Americans also have higher rates of untreated mental health disorders and higher rates of emergency department visits for mental health ailments. ${ }^{48}$ Because of severe poverty in this primarily African-American free clinic population, this may be an area requiring immediate attention in terms of further research, observation, and intervention.

Similar to national trends, women had higher rates of some mental health disorders than men. ${ }^{49}$ Part of the disparity in mental health disorder rates between men and women in this population may be 
because of reporter bias: men tend to report mental health complaints less often than women. ${ }^{50,51} \mathrm{Re}-$ search also suggests, though, that there is a real difference between men and women, ${ }^{52,53}$ and part of the reason for this may be the different responsibilities and roles held by women in poverty communities and the exposure of low-income people to violence, homelessness, incarceration, and the foster care system. ${ }^{54,48}$ Many low-income AfricanAmerican households are led by single mothers. Maintaining access to food, support, and general control over one's life can take a toll on people in tenuous circumstances. Resource loss and food insufficiency have been connected to poor mental health (eg, depression and anxiety). ${ }^{55,56}$ This psychosocial stress and anxiety may cause or exacerbate the physical health problems commonly experienced by women in poverty. Higher daily stress is connected to higher cardiovascular activity (higher blood pressure), overeating, and torso weight gain. ${ }^{45,57,58}$ This may, then, be part of the reason for the higher obesity and hypertension rates in women as well.

Approximately 1 in 5 adults (20.9\%) and nearly $30 \%$ of adults living below the poverty level in the United States were current smokers in $2005 .{ }^{59}$ The rate of adults who smoke in this free clinic population $(40 \%)$ vastly exceeds these rates. Thirteen percent (54 of 410) of this clinic's CAGE respondents had a positive score compared with a rate of $11.3 \%$ in the regional sample in which CAGE was also administered. Psychosocial stress may be connected to substance use and abuse in low-income populations. Alcohol and tobacco may be coping strategies for stressful life situations. ${ }^{60}$ The association between poor mental health and both smoking and alcohol use in this research seems to support this, although it could be that substance use is causing mental health problems rather than being used to alleviate them.

Finally, not having access to health care, which is one of the defining reasons patients come to a free clinic, is linked to poor physical and mental health. Those who lack adequate access to health care are not able to manage their chronic disease as well as those with consistent access to a regular source of care. ${ }^{61,62}$ Because they are under- or uninsured they may not have a regular physician and thus receive inconsistent care with poor follow-up for health concerns and treatments. ${ }^{38,63}$ These disadvantages are compounded by the trend that low- income, uninsured people often have less healthrelated knowledge, which impairs their ability to seek care when necessary and ask appropriate questions. ${ }^{64}$

This study of patients in a student-run, free medical clinic has some limitations. The health risk assessment questionnaire was given to all patients presenting at the clinic, however, this number was not recorded and not all patients returned the form. Thus, it is not possible to calculate a precise response rate (although observations suggest it was high). Second, demographic and some health status data are based on self-report and are subject to bias. In addition, many questionnaires were not completely filled out and it is not possible to determine the impact of missing data on the results, although again, this is thought to be minimal.

Although these data may be immediately relevant only to this particular population, it is useful to compare findings to the regional and national data to help determine what resources are lacking in the community. In this way, the methods in this study serve as a model for other free medical clinics to understand and support their populations. Results from this analysis will help the clinic staff to better address the needs of the population by establishing additional services that target hypertension, heart disease, obesity, diabetes, and mental health disorders. Potential applications also include helping the staff at the clinic establish "red flags" for identifying at-risk patients. For example, among the female patients, the staff may screen more carefully for mental health disorders given the prevalence of disorders indicated by the PRIME-MD and the known disparity in treatment for mental health disorders among African-American patients.

Information from this study will also aid in the orientation of medical student volunteers. Many students have never worked with low-income, urban populations and may be unfamiliar with the types of health problems that are prevalent. In the free clinic setting, they obviously benefit from their opportunity to see and diagnose various pathologies, the acquisition of medical skills, and the personalized attention from the attending physician. They may, however, not be versed in social and cultural norms of populations different from themselves and they may be unaware of how financial issues can have such a broad-reaching effect on health and well-being. Conversely, experienced medical students and physicians may be very well 
versed in these aspects of an underserved population, but it may be entirely different from this one (eg, an Appalachian population). Through information sharing and increased familiarity and awareness, medical students may be able to provide better care to a poorly served sector of our population. This could potentially improve the care that minority and low income patients receive long-term and could perhaps help diminish the vast disparity.

On a broader scale, this study highlights the problems with the health care system in the United States, particularly when compared with countries with universal health coverage. Patients come to this clinic because they lack insurance, they cannot afford co-pays, or they want to avoid the emergency department. They are being underserved by the system. Further, they are a high-risk population with a high rate of unemployment, with nearly $70 \%$ earning less than $\$ 10,000$ per year. In addition to having limited resources, they are more likely to become ill. It is hoped that this analysis promotes an understanding of the health and social problems faced by people who seek care at this study clinic and contributes to the body of data on demographic and social correlates of health risk among uninsured or underinsured African-Americans.

We thank Gareth Lema for organizing and de-identifying the patient database and Andrew Danzo for his editorial assistance.

\section{References}

1. World Health Organization. World Health Report, 2000. Geneva: World Health Organization; 2000.

2. World Health Organization. World Health Report, 2006. Geneva: World Health Organization; 2006.

3. United States Census Bureau. Health Insurance Coverage 2005 Highlights. Available at http://www. census.gov/hhes/www/hlthins/hlthin05/hlth05asc. html. Accessed 12 June 2007.

4. United States Census Bureau. State and County QuickFacts, 2005. Available at http://quickfacts. census.gov/qfd/states/36000.html. Accessed 12 June 2007.

5. DeHavas-Walt C, Proctor BD, Lee CH, United States Census Bureau. Income, poverty, and health insurance coverage in the United States: 2005. Available at http://www.census.gov/prod/2006pubs/p60231.pdf. Accessed 12 June 2007.

6. O'Hara B, Doyle P, United States Census Bureau. Medical out-of-pocket expenditures and alternative poverty measures. Available at http://www.census. gov/hhes/www/povmeas/papers/moop\%20paper. pdf. Accessed 26 January 2007.
7. Winerman L. The uninsured in America: who are the uninsured? Available at http://www.pbs.org/newshour/ indepth coverage/health/uninsured/whoaretheuninsured. html. Accessed 12 June 2007.

8. Schwartz JL. First national survey of free medical clinics 1967-69. HSMHA Health Rep 1971;86:77587.

9. Schatz BE, Ebrahimi F. Free clinic patient characteristics. Am J Public Health 1972;62:1354-63.

10. Geller S, Taylor BM, Scott HD. Free clinics helping to patch the safety net. J Health Care Poor Underserved 2004;15:42-51.

11. Albritton TA, Wagner PJ. Linking cultural competency and community service: a partnership between students, faculty, and the community. Acad Med 2002;77:738-9.

12. Bennard B, Wilson JL, Ferguson KP, Sliger C. A student-run outreach clinic for rural communities in Appalachia. Acad Med 2004;79:666-71.

13. Steinbach A, Swartzberg J, Carbone V. The Berkeley Suitcase Clinic: homeless services by undergraduate and medical student teams. Acad Med 2001;76:524.

14. Czarnecki C, Crane S, Morley JE, Flaherty JH. A student-run Geriatric Home Health Care Program. Acad Med 2001;76:199.

15. O'Malley PM, Russell MC, Brewer K, Campbell J, Morris T, Graham R. Get PHED up!! A student initiative to provide preventive healthcare information to emergency department patients. N C Med J 2003;64:157-60.

16. Der DE, You YQ, Wolter TD, Bowen DA, Dale LC. A free smoking intervention clinic initiated by medical students. Mayo Clin Proc 2001;76:144-51.

17. Simpson SA, Long JA. Medical student-run health clinics: important contributors to patient care and medical education. J Gen Int Med 2007;22:352-6.

18. Beck E. The UCSD Student-Run Free Clinic Project: transdisciplinary health professional education. J Health Care Poor Underserved 2005;16:20719.

19. Davenport BA. Witnessing and the medical gaze: how medical students learn to see at a free clinic for the homeless. Med Anthropol Q 2000;14:310-27.

20. Moskowitz D, Glasco J, Johnson B, Wang G. Students in the community: an interprofessional student-run free clinic. J Interprof Care 2006;20:254-9.

21. US Department of Health and Human Services, Health Resources and Services Administration. Health Professional Shortage Areas. Available at http://hpsafind.hrsa.gov/HPSASearch.aspx. Accessed 30 January 2007.

22. United States Census Bureau. American FactFinder. Available at http://factfinder.census.gov/home/saff/ main.html. Accessed 26 January 2007.

23. Niescierenko ML, Cadzow RB, Fox CH. Insuring the uninsured: a student-run initiative to improve access to care in an urban community. J Natl Med Assoc 2006;98:906-11. 
24. Koreishi S, Zayas L, Fox A. Qualitative community assessment of a student-run free medical clinic. Proceedings from the North American Primary Care Research Group conference, Orlando, Florida, October 2004.

25. King $M$. At risk drinking among general practice attenders: validation of the CAGE questionnaire. Psychol Med 1986;16:213-7.

26. Maisto SA, Saitz R. Alcohol use disorders: screening and diagnosis. Am J Addict. 2003;12(Suppl 1):S1225.

27. Mayfield D, McLeod G, Hall P. The CAGE questionnaire: validation of a new alcoholism screening instrument. Am J Psychiatry 1974;131:1121-3.

28. Spitzer RL, Kroenke K, Williams JB. Validation and utility of a self-report version of PRIME-MD: the PHQ primary care study. Primary Care Evaluation of Mental Disorders. Patient Health Questionnaire. JAMA 1999;282:1737-44.

29. Spitzer RL, Williams JB, Kroenke K, Hornyak R, McMurray J. Validity and utility of the PRIME-MD patient health questionnaire in assessment of 3000 obstetric-gynecologic patients: the PRIME-MD Patient Health Questionnaire Obstetrics-Gynecology Study. Am J Obstet Gynecol 2000;183:759-69.

30. Aber J, Bennett N, Conley D, Li J. The effects of poverty on child health and development. Annu Rev Public Health 1997;18:463-83.

31. Fiscella K, Franks P. Poverty or income inequality as predictor of mortality: longitudinal cohort study. BMJ 1997;314:1724-7.

32. Wagstaff A, van Doorslaer E. Income inequality and health: what does the literature tell us? Annu Rev Public Health 2000;21:543-67.

33. Subramanian SV, Belli P, Kawachi I. The macroeconomic determinants of health. Annu Rev Public Health 2002;23:287-302.

34. Dye T. The social epidemiology of public pregnancies: maternal and child health services in Appalachia [dissertation]. Buffalo (NY): State University of New York at Buffalo; 1993.

35. Crooks D. Food consumption, activity, and overweight among elementary school children in an Appalachian Kentucky community. Am J Phys Anthropol 2000;112:159-70.

36. Newman K. No shame in my game: the working poor in the inner city. New York: Russell Sage Foundation; 1999.

37. Meade M, Earickson R. Medical geography. 2nd ed. New York: The Guilford Press; 2000.

38. Becker G, Newsom E. Socioeconomic status and dissatisfaction with health care among chronically ill African Americans. Am J Public Health 2003;93: 742-8.

39. Keis RM, DeGeus LG, Cashman S, Savageau J. Characteristics of patients at three free clinics. J Health Care Poor Underserved 2004;15:603-17.

40. Gallo LC, Bogart LM, Vranceanu AM, Matthews
KA. Socioeconomic status, resources, psychological experiences, and emotional responses: a test of the reserve capacity model. J Pers Soc Psychol 2005;88: 386-99.

41. Croft JB, Strogatz DS, James SA, et al. Socioeconomic and behavioral correlates of body mass index in black adults: the Pitt County Study. Am J Public Health 1992;82:821-6.

42. Tumiel L, Schieder J, Taylor J. Western New York Adult Health Risk Assessment, 1999 Final Report. Buffalo (NY): State University of New York at Buffalo, Department of Family Medicine, Office of Research and Development; 2000.

43. Chung C, Myers Jr S. Do the poor pay more for food? An analysis of grocery store availability and food price disparities. J Consumer Affairs 1999;33: 276-96.

44. Nelson M, Bowser R, Lugton B, Murray-Bachman R, Jackson MY, Wolman PG. Problem of changing food habits: reaching disadvantaged families through their own food cultures. In: Karp RJ, ed. Malnourished children in the United States: caught in the cycle of poverty. New York: Springer Publishing Company; 1993:194-211.

45. Gluck ME, Geliebter A, Lorence M. Cortisol stress response is positively correlated with central obesity in obese women with binge eating disorder (BED) before and after cognitive-behavioral treatment. Ann N Y Acad Sci 2004;1032:202-7.

46. Goldbacher EM, Matthews KA, Salomon K. Central adiposity is associated with cardiovascular reactivity to stress in adolescents. Health Psychol 2005;24: 375-84.

47. Kessler RC, Chiu WT, Demler O, Walters EE. Prevalence, severity, and comorbidity of twelvemonth DSM-IV disorders in the National Comorbidity Survey Replication (NCS-R). Arch Gen Psychiatry 2005;62:617-27.

48. U.S. Department of Health and Human Services. Mental Health: A Report of the Surgeon GeneralExecutive Summary. Rockville (MD): US Department of Health and Human Services; 1999.

49. Kessler RC, Berglund P, Demler O, et al. The epidemiology of major depressive disorder: results from the National Comorbidity Survey Replication (NCS-R). JAMA 2003;289:3095-105.

50. Vredenburg K, Krames L, Flett G. Sex differences in the clinical expression of depression. Sex Roles 1986; 14:37-49.

51. Hunt M, Auriemma J, Cashaw AC. Self-report bias and underreporting of depression on the BDI-II. J Pers Assess 2003;80:26-30.

52. Piccinelli M, Wilkinson G. Gender differences in depression. Critical review. Br J Psych 2000;177: 486-92.

53. Mental Health America. Depression in women. Available at http://www.nmha.org/index.cfm? objectid= 
C7DF952E-1372-4D20-C8A3DDCD5459D07B. Accessed 18 June 2007.

54. Nolen-Hoeksema S. Sex differences in unipolar depression: evidence and theory. Psychol Bull 1987; 101:259-82.

55. Heflin CM, Siefert K, Williams DR. Food insufficiency and women's mental health: findings from a 3-year panel of welfare recipients. Soc Sci Med 2005; 61:1971-82.

56. Hobfoll SE, Johnson RJ, Ennis N, Jackson AP. Resource loss, resource gain, and emotional outcomes among inner city women. J Pers Soc Psychol 2003; 84:632-43.

57. Troxel WM, Matthews KA, Bromberger JT, SuttonTyrrell K. Chronic stress burden, discrimination, and subclinical carotid artery disease in African American and Caucasian women. Health Psychol 2003;22:300-9.

58. James GD, Bovbjerg DH. Age and perceived stress independently influence daily blood pressure levels and variation among women employed in wage jobs. Am J Hum Biol 2001;13:268-74.

59. Centers for Disease Control and Preventino. Tobacco use among adults-United States, 2005. MMWR Morb Mortal Wkly Rep 2006;55:1145-8.

60. Wilkinson R. Unhealthy societies: the afflictions of inequality. London: Routledge; 1996.

61. Becker G. Effects of being uninsured on ethnic minorities' management of chronic illness. West J Med 2001;175:19-23.

62. Becker G, Gates RJ, Newsom E. Self-care among chronically ill African Americans: culture, health disparities, and health insurance status. Am J Public Health 2004;94:2066-73.

63. Becker G. Deadly inequality in the health care "safety net": uninsured ethnic minorities' struggle to live with life-threatening illnesses. Med Anthropol Q 2004;18:258-75.

64. Flores G, Abreu M, Sun D, Tomany SC. Urban parents' knowledge and practices regarding managed care. Med Care 2004;42:336-45. 